\title{
The Urban Heat Island phenomenon modelling and analysis as an adaptation of Maghreb cities to climate change
}

\author{
Kaoutar Ouali ${ }^{1}$, Khalid El Harrouni ${ }^{2}$, Moulay Larbi Abidi ${ }^{1}$, Youssef Diab ${ }^{3}$ \\ ${ }^{1}$ Laboratory of Civil Engineering, Ecole Mohammadia d'Ingénieurs, Université Mohammed 5, Rabat, Morocco \\ ${ }^{2}$ Laboratory Energy, Sustainability and Ambiances, Ecole Nationale d'Architecture, Rabat, Morocco \\ ${ }^{3}$ Lab'Urba, Université Paris-Est-Marne-la-Vallée, Champs-sur-Marne, France
}

\begin{abstract}
The modeling of the urban microclimate, in particular the phenomenon of the Urban Heat Island (UHI), is becoming increasingly essential for city planning and urban design. The phenomenon analysis is henceforth possible thanks to the increase in computational power, the link between simulation tools and urban databases, which allow to represent explicitly the characteristics of the urban microclimate and to better understand its effects, through the analysis and evaluation of the different impacts of the urban climatic or anthropogenic contributors (urban morphology, land use, building sites, albedo, ...). However, the choice of the scaleof the study depends on a balance between the precision of the modeling, the capacities of calculation and the availability and reliability of the data.The UHI phenomenon has been the subject of several research studies in the European countries since the 2000s. Thispaper focuses mainly on the description of the phenomenon, the different methodsused to evaluate and modeled its impacts, using some approaches for mitigating these ones. The contribution aims to highlight the phenomenon of the UHI based on a bibliographic study of the latest research on this topic in Maghreb cities. The state of art focuses on the progress made during the last 15 years taking into account the UHI in the different strategies for adapting cities to climate change and for improving their resilience.
\end{abstract}

\section{Introduction}

The build environment is place of radiative, thermal, dynamic and hydric processes which modify the climate of the city. Urban environment stores some heat during day but releases little during night contrary to rural areas.In a current context where the consequences of the urban development must be mastered, the knowledge and the modeling of these various urban physical phenomena became an important stake. The controlof the energy consumptions of cities, characterization and quantification of the Urban Heat Island (UHI) impact, the study of the internal and external thermal comfort of the space urban users, are widely boundto the development of the knowledgeon the interactions between the city, the climate and the energy.

The UHI is one of the most documented phenomena in the scientific literature; it contributes to global warming and leads to an adaptation of the city's sustainable planning policies. The evaluation of the maximum amplitude of the empirical as the case of the large North American and European agglomerations [1] or with the models based on the energy balances surface or volume.It is very difficult to compare UHI studies because of the multiplicity of used methodologies, the simplistic historical vision of the single city center and the clear delimitation of urban space. Nowadays, the reality is more complex.We cannot quantify the difference in temperature due to urbanization alone without knowing the original conditions of the site; natural microclimatic phenomena must make the comparison even more difficult.

The present proposed overview cannot be exhaustive. Nevertheless, it provides an illuminating insight into the state of the issue and the progress made in recent years about the scientific knowledge of this phenomenon. This research carried out also the approaches to study the UHI, and some expected results of these studies, particularly in the Maghreb countries, notably in Morocco.

\section{Literature Review}

\subsection{Characterization of the UHI}

UHI refers to the excess air temperature in the urban canopy relative to the surrounding rural areas. The Urban Canopy Layer (UCL) is the layer of air closest to the surface in cities, extending upwards to approximately the mean building height.See schematic representation at figure 1.Each UHI has its own unique features and the quantification of this phenomenon depends on the specific city. Several studies have subsequently demonstrated that the level temperature measurement at the streets did not matter because the air temperature 
varies little in the street when it is more than one meter from the walls or the road [2, 3].In the literature, the UHI observation methods listed are based on: collecting statistics data of the temperature difference between urban and rural meteorological stations $[4,5,6]$; tendency study of temperature for a meteorological station whose environment is urbanized [7, 8, 9]; comparison of the temperature trend observed for several stations whose environment evolves differently [10]; observation by means of a network of fixed stations [11], observation along a path using vehicle [12].

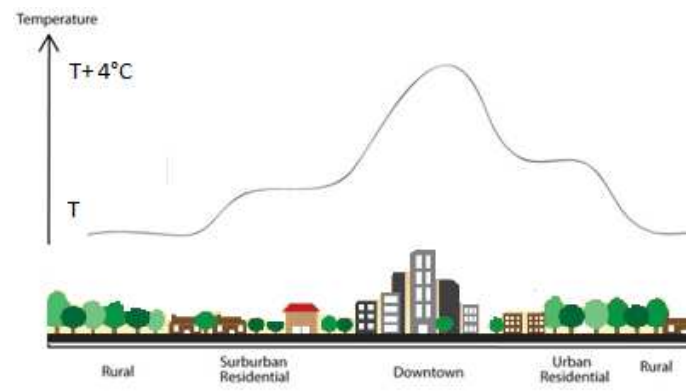

Fig.1.Schematic representation of the urban heat island profile

Numerous studies show that city centers that concentrate large quantities of buildings, economic activities and leave less space for vegetation and stretch of water are more affected by the UHI impacts [13].

\subsection{Energy balance of an urban surface element}

The development of the energy balance of the city requires the modeling of energy and mass transfers which are the basis of microclimatic processes. The atmosphere is a thermal machine whose energy state depends on the balance between these fluxes [14]. The overall surface of the soil is a patchwork of irrigated or not irrigated plant, mineral and synthetic surfaces with completely different radiative, thermal, aerodynamic and hydric properties [15]. Moreover, it is difficult to calculate the urban energy balance within the urban canopy, because of the accentuate "pleating" of surface, the geometric heterogeneity, the diversity of the thermo-physical properties of urban developments, and the various unknowns such as the uncertainty of the composition underground or the unpredictability of the quantity and quality of the energy equipment inside the buildings [16].

A modeling of urban surface elements or urban facets is required depending on the targeted spatial and temporal scale [16].While the first one is more used to the energy comparison of neighborhoods or to study energy transfers of the larger climate scale, the second is more suitable for the treatment of energy interactions between building and its immediate urban environment.

The energy balance of a system is the algebraic sum of the energy fluxes that exchange with its environment. Simply, it is the spatial scale of modeling that modifies the terms of the balance sheet. On a large scale, the usual practice is to aggregate the physical variables of the field, the fluxes, in order to be interested only in their average values. While on a small scale, we are interested in the singular phenomena, specific to the human scale, the comfort, the safety, and the energy consumption. The energy balance of a real surface mesh of an urban object in a steady state (figure2),is expressed in flux density $\left[\mathrm{W} . \mathrm{m}^{-2}\right][17,18,19,20]$ according to equation (1):

$Q^{*}+Q_{F}=Q_{H}+Q_{E}+\Delta Q_{S}\left(+\Delta Q_{A}\right)(1)$

where:

$\mathrm{Q}^{*}$ is the net all wave radiation;

$\mathrm{Q}_{\mathrm{F}}$ is the anthropogenic heat flux corresponds to the sum of the heat outputs of motor vehicles, buildings, industries, urban facilities as well as human metabolism; $\mathrm{Q}_{\mathrm{H}}$ is the turbulent flow of sensible heat due to the aerodynamic heat transfer between the solid surfaces and the air mass, due to their temperature difference;

$\mathrm{Q}_{\mathrm{E}}$ is the turbulent flow of latent heat due to the release of water vapor by natural soils, plant surfaces and porous surfaces;

$\Delta \mathrm{Q}_{S}$ is the change in the amount of heat stored by the urban area; $\Delta \mathrm{Q}_{\mathrm{A}}$ is the net energy (sensible and latent) advection (horizontal transport).

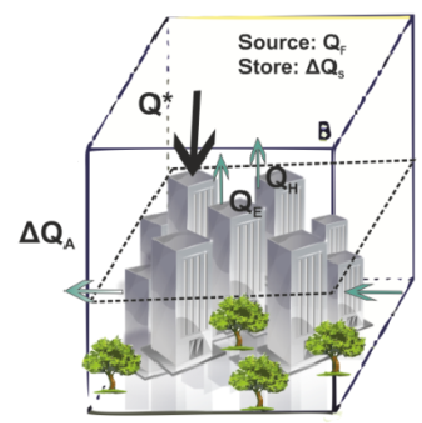

Fig.2.The energy balancean urban building air volume(OKE, 1978).

The term $\mathrm{Q}^{*}$ represents the net flux of radiation over the entire electromagnetic spectrum. It is decomposed into two bands of wavelengths: solar radiation of 0.3 to $3 \mu \mathrm{m}$ (visible from 0.38 to $0.76 \mu \mathrm{m}$ ) and thermal infrared (IRT) of 3 to $100 \mu \mathrm{m}$.

The radiative balance $\left(\mathrm{Q}^{*}\right)$ in $\left[\mathrm{W} . \mathrm{m}^{-2}\right]$ :

$Q^{*}=L \downarrow-L \uparrow+(1-\alpha) K \downarrow$

where:

$\alpha$ is the albedo defined as the ratio of the amount of light or energy that is reflected back into the atmosphere by any particular surface,

$\mathrm{L} \uparrow$ is the net IRT flux exchanged with the surfaces of buildings, soil and all other solid surfaces belonging to the urban canopy,

$\mathrm{L} \downarrow$ is the net IRT flux exchanged with the atmosphere,

$\mathrm{K} \downarrow$ is the overall solar flux incident.

The incident global solar flux $\mathrm{K} \downarrow$ is the sum of three terms, the flux coming directly from the sun, the diffuse solar flux coming from the reflection and multidirectional diffusion of the direct solar rays by the atmospheric particles and the diffuse solar flux coming from the multireflections on theothers urban surfaces and trapped in the canopy.

\subsection{Factors affecting UHI}

Many controllable and uncontrollable factors which contribute to UHI have been categorized [21]. This include the temporary effect variables, such as air speed 
and cloud cover and permanent effect variables like green areas, building material, and sky view factor and cyclic effect variables such as solar radiations and anthropogenic heat sources.Controllable factors include urban parameters such as city size, influenced by urban populations and densities, density of built-up areas including land use, distance between buildings and average height of buildings, urban geometry including street orientations, $\mathrm{H} / \mathrm{W}$ ratio of street $(\mathrm{H}$ and $\mathrm{W}$ refer to the height and the width of the street canyon, and sky view factor (SVF), which is the visible area of the sky from a given surface. Apart of urban geometry, surfaces including buildings and pavements that are generally composed of dark materials that readily absorb and store the sun's heat. Most building materials are also impermeable thus further exacerbating the warming trend in cities. The high levels of urban air pollution as well as the urban heat generations are an others reason for the heat island formation.Natural parameters such as temperature, cloud cover and wind have a significant impact on the UHI. The natural location of a city also plays a role since its physical characteristics that include topography, mountain ranges and hills, rivers and/or other water bodies can determine the extent to which UHI can be affected.

\subsubsection{Materials andcoatings}

The ability of an urban material to capture heat and restore it at night is characterized by its inertiadepending on its thermal capacity, conductivity, diffusivity and effusiveness. Another significant anthropogenic factor that has a major impact on the UHI phenomenon is the albedo property of urban surface materials. A low albedo means a surface reflects a small amount of the incoming radiation and absorbs the rest. On the other hand, ahigh albedo means a surface absorbs a small amount of the incoming radiation and reflects the rest. The albedo of urban materials is generally lower than of materials found in the countryside. These materialstherefore increase the temperature and their inertia is higher, so they absorb the heat to restore it during the night period, preventing the refreshing of the city [22].Rough and dark surfaces absorb more radiation than smooth, flat and clear surfaces and reach a higher temperature. Smooth, flat surfaces are warmer than those that are rough and curved. [23]. Materials such as marble, mosaic and stone reach lower surface temperatures and thus contribute less to the effect of UHI.By studying the variation in the solar reflectivity of concrete, their composition, aging and climatic exposure have been shown to significantly alter their albedo [24].

\subsubsection{Urban morphology}

The urban morphology refers to the shape, dimension and spacing of buildings within a city, which together add to the amount of radiation received, reflected and emitted by the urban infrastructure. In urbanized areas, spaces and built environments are often obstructed, either fully or partially, by building blocks that quickly become large thermal masses triggering the build-up of UHI.

Shading is the second parameter affecting the radiative balance. Indeed, the shadows that the buildings make on the outside spaces limit the rise in temperature of the materials. These shadows are all the more important as the prospect of the urban construction is high [25].The orientation of the streets is also of particular importance. The orientation of urban streets and islets in relation to prevailing winds influences wind speed and turbulence [26]. The link between the wind speed inside and above a canyon street has also been shown: the wind inside the street is slowed down, its direction is changed and turbulent flows are generated. This link is largely influenced by the orientation of the street in relation to the wind and by the prospect of the street.Toudert[27] carried out an investigation on the contribution of street design toward the development of a comfortable microclimate for pedestrians during the hot and dry summertime of Ghardaia in Algeria. The main factors investigated in the study comprised: height-width ratio $(\mathrm{H} / \mathrm{W})$, street orientation, overhanging facades, and the use of galleries and rows of trees; they were able to determine that street orientation and $\mathrm{H} / \mathrm{W}$ ratio of streets have the most significant impact on the microclimate in urban canyons.Radiative trapping is the third factor, also linked to urban geometry, for a highly prospective urban form, the solar rays undergo multiple reflections and heat the surfaces that compose the street before partially emerging towards the atmosphere. The temperature inside the canyon streetwill therefore be increased (Figure 3). Infrared rays emanating from heated urban materials are trapped in the same way [28].
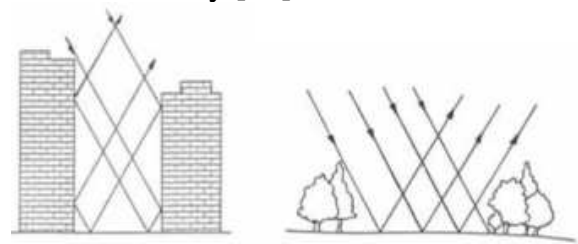

Fig.3. Illustration of radiativetrapping (Griffiths, 1976)

\subsubsection{The natural canopy}

The landscape in rural areas is typically dominated bylarge vegetated surfaces or open spaces. Rural temperatures are therefore lower andcooler than their surrounding urban areas due to shading provided by the trees andvegetation, and the process of evapotranspiration in which plants release water fromthe earth's surface and accordingly dissipate ambient heat into the air. In contrast, urban areas are characterized by dry, impermeable and darkmineralized surfaces consisting primarily of roofs, pavements, roads and parking lots thattypically reflect less and absorb more of the sun's energy. As urbanization expandstherefore, more vegetation is lost, and more surfaces become paved and covered withbuildings thus resulting in lower levels of moisture and accordingly heat losssuch us in (figure 4). Indeed, the phase change of water by evaporation is accompanied by heat absorption. For example, during a summer rainfall that supplies $5 \mathrm{~mm} / \mathrm{m}^{2}$ of water, 8 times less water evaporates in urban areas than in rural areas within the next twenty-four hours. The difference in the amount of heat taken from the environment corresponds to $2.5 \mathrm{KWh} / \mathrm{m}^{2}$ in twenty-four hours, slightly more 
thantwice the heat resulting from human activities in summer [29].

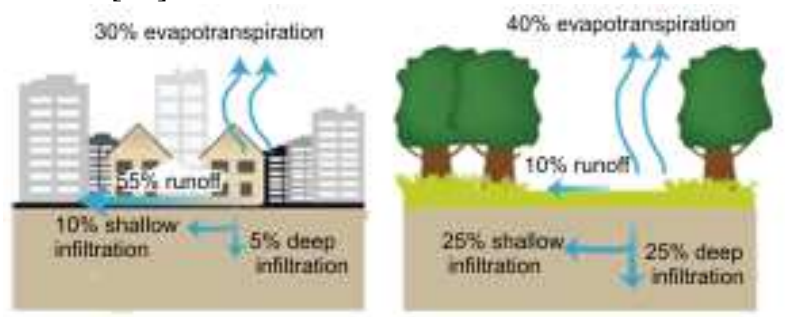

Fig.4.Evapotranspiration in urban areas (USEPA, 2008)

In the study of the mostoptimal urban street designs on thermal microclimate for example, Toudert[27] highlighted the importance of having rows of shade trees in urban canyonsdue to the important role they play in enhancing thermal comfort levels of urban streets.

\subsubsection{Anthropogenic heat emissions}

In urban areas, the high density of concentration on the human activities increases the anthropogenic heat releases of heating, air conditioning, transport and industrial activities. These anthropogenic heat fluxes are different from the city to another: Oke[18] has been able to highlight annual values, ranging from $3 \mathrm{~W} / \mathrm{m}^{2}$ to $117 \mathrm{~W} / \mathrm{m}^{2}$. While the amount of these releases depends on the climate (Montreal has one of the highest amounts of anthropogenic releases), it also depends heavily on building density and population of the city [18, 28, 30].

\subsection{Effects of urban heat islands}

The consequences of the UHI remain difficult to predict, and very variable according to climates.It is difficult to decide between reducing heating consumption and increasing consumption of air conditioning, especially in climate change context.Among the consequences of the urban heat island effect are the reduction in the efficiency of passive refreshing modes, air pollution, increased discomfort, and significant risks to human health and biodiversity [28] as well as the increase in energy consumption [31].

\subsubsection{Impact on energy consumption}

Numerous studies show that the UHI is both the cause and the consequence of the increase in energy consumption at the city [16].The case of Athens city is pertinent, the maximum intensity of the UHI can in fact reach $12^{\circ} \mathrm{C}$, and an increaseof 3 to $5 \%$ in electrical consumption is observed when the temperature increases by $1^{\circ} \mathrm{C}$ [32].Santamouris [33] carried out a study in Athens in 1996, showing that the maximum intensity of the UHI can reach on average for the city center of Athens near $12^{\circ} \mathrm{C}$, and even $16^{\circ} \mathrm{C}$ for the hyper center. It can be seen thatfor the city of Athens, where the mean heat island intensity exceeds $10^{\circ} \mathrm{C}$, the cooling load of urbanbuildings can be doubled, the maximum power ofelectricity for cooling purposes may be tripled in particular at higher set point temperatures, whereas the minimum coefficient of performance COP value of the air conditioners may be reduced by up to $25 \%$ due to higher ambient temperatures. According to Akbari [34] the analysis of temperature trends in several large cities in the United States indicatesthat temperature increases are responsible for $5-10 \%$ of the energy consumption for air conditioning.

In 2005, Bozonnet[31] also revealed the vicious circle linked to the mutual influences of air conditioning systems and the UHI (Figure 5).

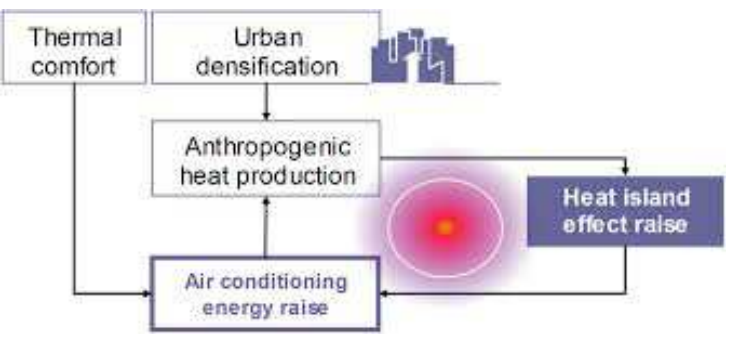

Fig.5. The vicious circle linked to the mutual influences of air conditioning systems and the UHI Bozonnet (2005)

\subsubsection{Impact on outdoor comfort}

The main external physical parameters that occur in thermal comfort are air temperature, humidity, solar and infrared radiation received, and air movements or convective influences (wind) [28]. All these elements are influenced by the form, the urban structure. However, a purely physiological and quantitative approach is inadequate to characterize external comfort. Furthermore, parameterthat strongly influence the feeling of comfort, there is a subjective assessment of the comfort that depends on the person and this psychological adaptation to the outside seems to be important [35]. The thermoradiative energy balance of the external spaces is closely linked to the nature and morphology of the building arrangements. Athamena[36] studied through modeling and numerical simulation the relationship between specific urban morphology Eco-neighborhoods, microclimate and thermal comfort in outdoor spaces resulted in recommendations for the design of a comfortable outdoor urban space, for example, future neighborhoods should be constructed as self-contained porous buildings opening the internal public spaces to the incident winds, thus favoring the ventilation of spaces and limiting the corner effect which generates unpleasant heat sensations. Moreover, theorganization of the district around an open internal space connected to the outside by a crosswalk advances the dissipation of the heat accumulated during the day.

\section{Approaches to Mitigation of $\mathrm{UHI}$ in Maghreb Cities}

\subsection{Case of Maghreb cities}

There are few studies on the microclimate and human comfort of urban areas in hot dry climates.A study carried out in Constantine in Algeria with ENVI-met a pronostic three-dimentional climate model simulating the interactions between atmosphere, soil, vegetation and building on micro-scale level demonstrated that the urban canyon with a large $\mathrm{H} / \mathrm{W}$ ratio is most advantageous for the outdoor thermal comfort in the summer provided that to choose the orientation offeringmore
ventilation[37].The wind also represents a 
ratherperceptible element of the urban microclimate; it is one of the factors which determine the success or the failure of a public space, asit strongly influences the thermal comfort. It can be a source of ventilation in summer, or a source of nuisances in winter.Also ofJijel in Algeria; a simulations highlighted the effect of urban geometry on wind flow and natural outdoor ventilation in the city. The study has shown that the geometry of the ground plane and the arrangement of the building determine and model the wind flow. Because of humid climate and strong winds, an exploded geometry is not recommended for a site at high altitude. On the other hand, it will be appropriate for low lying areas [38].

The Sfax agglomeration in Tunisia was also studied on the trend of rising air temperatures, the spatial variability of the UHI and the impact of inadequate development choices on the local climate on the intensification of global warming. Using the satellite tools, the study showed that hot surfaces correspond to densely built spaces. The spreading, densification of the built-up areas between 1987 and 2007 and the vertical evolution that is known in the city are in line with the expansion of the hot surfaces. The temperature measurements in downtown Sfax, have shown that some recent developments such as the vertical trend and the use of curtain walls have worsened the warming. The urban design of the northern countries such as the curtain walls, neglect of the aerodynamics of the city and the scarcity of green spaces are inadequate to the local climate.

In future developments, urban planners should have relatively large streets oriented obliquely to the prevailing wind so that it benefits both facades and streets [39]. It seems sensible to impose, for new constructions, standards better suited to a warm climate.

\subsection{Case of Moroccan cities}

The topic of the UHIin Morocco was first discussed in 2006, as part of a cooperation program between LPEE (Laboratoire publicd'essais et d'études)and the University of Lund (Sweden), in Fez city comparative study between two districts with a different urban fabric: the urban traditionalarea in the medina (Seffarine), and the modern district on the outskirts (Adarissa), a standard of urban density and a low density urban neighborhood. The aim was to study the influence of the urban fabric and shape on the microclimate of the two neighborhoods.Johansson [40] proved that in hot dry climates a compact urban design with very deep canyons is preferable.

The study investigated theinfluence of urban geometry on outdoor thermal comfort by comparing an extremely deep and a shallow street canyon in Fez city. Continuous measurements during the hot summer and cool winter seasons show that, by day, the deep canyon wasconsiderably cooler than the shallow one. In summer, the maximum difference was on average $6^{\circ} \mathrm{C}$ and as great as $10^{\circ} \mathrm{C}$ during thehottest days. However, during winter, the shallow canyon is the more comfortable as solar access is possible [40]. The main difference between the two districts is the level of the urban form: the configuration and density of the neighborhoods on the one hand, and the architecture and walls thermal characteristics of the building on the other. The urban form of modern districts has a heating effect on the microclimate. This influence can be seen mainly during the night and afternoon periods; the climate then being out of the comfort zone and it is sometimes necessary to air-condition. On the other hand, traditional neighborhoods with a high urban density have a regulatory impact on the microclimate in summer because they compensate for the large differences in daytime and nighttime temperatures which make it possible to maintain the climate for the most part in the comfort zone.In winter, the urban form of modern districts has a heating effect on the microclimate.

Casablanca, the largest industrial and commercial center in Morocco with rapid urbanization and explosive population growth, has also been the subject of two recent studies on the characterization and evaluation of the UHI by means of satellite tools $[41,42]$.

Landsat and MODIS data were combined in the simple biosphere model to assess the impact of urbanization on surface climate in Marrakech. A complete urbanization of the area would decrease its carbon uptake by 0.13 tons and increase its daytime surface temperature by $1.3^{\circ} \mathrm{C}$, with $5.72 \%$ increase in energy consumption [43].

\section{Conclusion}

In Maghreb cities notably in Morocco, urban planning is being revised; new approaches are being implemented, and it is the appropriate time to sensitize to take into account of these mitigation measures.The last urban development plan incorporated measures (econeighborhoods, urban agriculture, etc.) but it is not a question here of proposing only strategies that can be envisaged in the short and medium terms (increase in vegetated areas, the albedo of the surfaces ...), but also to understand if longer-term strategies have their place because of their potentially important effect on the intensity of the urban climate and more particularly of the UHI.Significant progress has been made in recent years in taking into account the UHI in the different strategies for adapting cities to climate change and in improving their resilience. Several studies have focused on this subject in cities of different climatic zones and have allowed the implementation of an adaptation strategy specific to each one: Tokyo, Barcelona, Seville, Montreal, Paris and Bayroute. The most advanced city in the field of adaptation is Tokyo where a systematic plan for watering streets is proposed and a strategy to open public parks is advocated during a heat wave. Paris else, takes the issue seriously following the 2003 heat episode.Moreover, consider this problem within the framework of a systemic approach incorporating the interactions between the different elements of the urban ecosystem has not yet been addressed in Maghreb cities.

\section{Bibliography}

1. Oke,T.R.Initial guidance to obtain representative meteorological observations at urban sites. Instruments and Observing Methods Report No. 81, WMO/TD No. 1250. (2006).

2. Nakamura, Y., et T. R. Oke, Wind, temperature and stability conditions in an east-west oriented urban canyon, Atmos. Environ., 22, 2691-2700.. (1988) 
3. Eliasson,I.Urban-suburban-rural air temperature differences related to street geometry. Physical Geography, 15(1), 122., (1994)

4. Ackerman, B., Temporal march of the chicago heat island. Climate Appl. Meteor24, 547-554, (1985)

5. Nasrallah, H. A., A. J. Brazel, et R. C. Balling Analysis of the Kuwait City urban heat island, Int. J. Climatol. 10, 401405. (1990)

6. Moreno-Garcia, M. C. Intensity and form of the urban heat island in Barcelona, Int. J. Climatol., 14, 705-710. (1994),

7. Tarleton, L. F., et R. W. Katz Statistical explanation for trends in extreme summer temperatures at Phoenix, Arizona, Journal of Climate, 8, 1704-1708 (1995),

8. Montávez, J. P., A. Rodríguez, et J. I. Jiménez A study of the urban heat island of Granada, Int. J. Climatol., 20, 899911. (2000)

9. Tereshchenko, I.E., et A.E.Filonov Air temperature fluctuations in Guadalajara, Mexico, from 1926 to 1994 in relation to urban growth., Int. J. Climatol.,21, 483-494. (2001),

10. Magee, N., J. Curtis, et G. Wendler The urban heat island effect at Fairbanks, Alaska, Theor. And Appl. Climatol., 64, 39-47. (1999)

11. Kuttler, W., A.-B. Barlag, et F. Roßmann Study of the thermal structure of a town in a narrow valley, Atmos. Environ.,30, 365-378. (1996)

12. Yamashita, S., allOn relationships between heat island and sky view factor in the cities of Tama River basin, Japan, Atmos. Environ., 20, 681-686. (1986)

13. Grégoire Pigeon. Les échanges surface-atmosphère en zone urbaine - projets CLU-ESCOMPTE et Capitoul Thèse: Physique de l'Atmosphère Université Toulouse III (2007)

14. Vinet, J. "Contribution à la modélisation thermo-aéraulique du microclimat urbain : Caractérisation de l'impact de l'eau et de la végétation sur les conditions de confort en espaces extérieurs". Thèse Ecole Polytechnique de Nantes. (2000).

15. Arnfield, A. Two decades of urban climate research: a review of turbulence, exchanges of energy and water, and the urban heat island. International Journal of Climatology,23:1-26. (2003).

16. Bouyer J., Modélisation et simulation des microclimats urbains : Étude de l'impact de l'aménagement urbain sur les consommations énergétiques des bâtiments. École NationaleSupérieured'Architecture de Nantes (2009).

17. Brutsaert, W. Evaporation into the atmosphere: theory, history and applications. Environmental Fluid Mechanics.Dordrecht, Holland. (1982).

18. Oke, T. R. Boundary layer climates.Londres, 2édition. (1987).

19. Mestayer, P. G.,Anquetin, S. Climatology of cities. In Diffusion and transport of pollutants in atmospheric mesoscale flow fields, volume 1 de ERCOFTAC series, pages 165-189.Netherlands. (1994).

20. Guyot, G. Climatologie de l'environnement : Cours et exercices corrigés. Dunod, Paris, 2e édition. (1999).

21. RIZWAN Ahmed Memon. A review on the generation, determination and mitigation of Urban Heat Island, Journal of Environmental Sciences20p/120-128 (2008).

22. Liebard, A. all. Concevoir, édifier et aménager avec le développement durable.Traité d'architecture et d'urbanisme bioclimatiques. Le Moniteur, 776 p. (2006)

23. Doulos, L.; Santamouris, M. \&Livada, I.Passive cooling of outdoor urban spaces: The role of materials.Solar Energy77, 231-249 (2004)

24. LevinsonH.F.,et al. The Mass Disruption of Oort Cloud Comets Science296, 2212 (2002)
25. ADOLPHE, L. all. SAGA Cités, Système d'Aide à la Gestion des Ambiances urbaines, Rapport final. MENRT, Action Concertée Incitative Ville, février (2002).

26. SACRE, Christian. Le confort dans les espaces extérieurs : analyse microclimatique. Nantes : Centre Scientifique et Technique du Bâtiment,138 p. (1983)

27. Ali- Toudert F., Mayer H. Numerical study on the effects of aspect ratio and orientation of an urban street canyon on outdoor thermal confort in hot and dry climate. Building and environement,41 (2), pp. 94-108 (2006).

28. Colombert, M. "Contribution à l'analyse de la prise en compte du climat urbain dans les différents moyens d'intervention sur la ville". Thèse Université Paris-Est, (2008).

29. DETTWILLER, J. L'évolution séculaire de la température à Paris. La Météorologie, ${ }^{\circ} 13$, p. 95-130. (1978)

30. RINGENBACH, Nicolas. Bilan radiatif et flux de chaleur en climatologie urbaine : mesures, modélisation et validation sur Strasbourg. Thèse Strasbourg I, 167 p. (2004)

31. Bozonnet, E. Impact des microclimats urbains sur la demande énergétique des bâtiments - Cas de la rue canyon. Thèse :Génie Civil, La Rochelle, 175 p. (2005)

32. Santamouris, M. ADNOT, J. ALVAREZ, S. et al. Cooling the cities - rafraichir les villes. Paris : Ecole des Mines de Paris-Les Presses, 263 p. (2004)

33. Santamouris, M., Papanikolaou, N., Livada, I., Koronakis, I., Georgakis, C. and Assimakopoulos, D. N. 'On the impact of urban climate to the energy consumption of buildings', Solar Energy, vol70, no 3, p201-216 (2001)

34. Akbari, H. POMERANTZ, M. TAHA, H. Cool surfaces and shade trees to reduce energy use and improve air quality in urban areas. Solar Energy, vol.70, n³, p. 295-310 (2001).

35. NIKOLOPOULOU, Marialena. STEEMERS, Koen. Thermal comfort and psychological adaptation as a guide for designing urban spaces. Energy and Buildings, vol.35, p. 95- 101 (2003)

36. Athamena K., Modelisation et simulation des microclimats urbains : étude de l'impact de la morphologie urbaine sur le confort dans les espaces extérieurs. thèse de doctorat de l'Ecole Centrale de Nantes (2012).

37. Bouchriba F., Impact de la géométrie des canyons urbains sur le confort thermique extérieur - Cas du Coudiat de Constantine - Thése. Universitementouri (2005)

38. Bouketta, Bouchahm and Y. Bouchahm, L'effet de la géométrie urbaine sur l'écoulement du vent et la ventilation naturelle extérieure Revue des Energies RenouvelablesV.15 $\mathrm{N}^{\circ} 04$ (2012)

39. Ali-Toudert F., Weidhaus J., Numerical assessment and optimization of a low-energy residential building for Mediterranean and Saharan climates using a pilot project in Algeria Renewable Energy101 327- 346 (2017)

40. Erik Johansson Influence of urban geometry on outdoor thermal comfort in a hot dry climate: A study in Fez, Morocco. Building and Environment41 1326-1338 (2006)

41. Bahi H. all. Effects of Urbanization and Seasonal Cycle on the Surface Urban Heat Island Patterns in the Coastal Growing Cities: A Case Study of Casablanca, Morocco, Remote Sens., 8, 829. (2016)

42. Azmi R., Saadane A., and Kacimi I. Estimation of spatial distribution and temporal variability of land surface temperature over Casablanca and the surroundings of the city International Journal of Innovation and Applied StudiesVol. 11 No. 1 Apr., pp. 49-57(2015)

43. Lachir A., Bounoua L., Ping Zhang Kurtis Messouli M. Modeling the Urban Impact on Semiarid Surface Climate: A Case Study in Marrakech, Morocco Canadian Journal of Remote Sensing, 42:379-395, (2016) 